\title{
"Tengo sobre mí los males de mi pueblo"." Interpelación y advertencia desde el quehacer martiano
}

\section{"I bave on me the evils of my people". Interpellation and warning from the work of José Martí \\ "Eu tenho em mim os males do meu povo." Interpelação e advertências com o trabalho de José Martí}

Marina Verdini-Aguilar

Universidad de Bahía Blanca

Argentina

Recibido: 3/8/2015 Aceptado: 30/10/2015 / http://dx.doi.org/10.15359/tdna.32-59.3

\section{Resumen}

Se propone un análisis histórico del ensayo Nuestra América, escrito por el intelectual revolucionario José J. Martí. Conocer y analizar los múltiples contextos históricos de nuestra América se constituyeron en una condición fundamental para concretar la praxis libertaria martiana, pues en nuestro presente también resultan vitales para cualquier abordaje que se proponga contribuir en la transformación de las plurales situaciones de dependencia y dominación que mutan, en tanto se transforma el sistema que las origina. Posicionándonos en este marco,

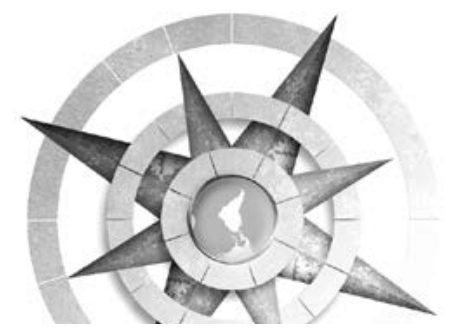

desde la labor de historiar, proponemos la construcción de una epistemología genuina cuyos contenidos interpelen al pensamiento, revisando sus modos habituales del pensar. El estudio de los múltiples y diversos textos martianos permite concebir la praxis de su autor como un complejo que asocia la historia de su propio presente revolucionario con una nítida crítica sui generis y contrahegemónica que consideramos todavía vigente.

Palabras clave: José Martí, historia, dominación, resistencia, emancipación, Cuba.

\section{Abstract}

The purpose of this article is to analyze, from a historical point of view, José Martî's essay 
Nuestra América. For Martí and his libertarian work, to investigate the different Latin American historical contexts was vital. This aspect is also very important for those studies which aim to contribute to the transformation of the different situations of domination and dependence. According to this framework and for our purposes, to build up a genuine epistemology, whose concepts question the usual thoughts and ways of thinking, results a fundamental issue. For this reason, we try to analyze Martís documentary corpus -composed of different types of literary genres- relating the history of his revolutionary present with his original and counterhegemonic criticism, which we consider is still valid.

Keywords: José Martí, history, domination, resistance, emancipation, Cuba.

"Pues no es un poeta el que vuelve del destierro, es el libertador que viene con su ejército de esclavos y prisioneros a luchar por su pueblo (...)" (Martínez Estrada, 1971, p. 10)

Durante las primeras décadas el siglo XIX, en las diversas regiones de nuestra América, cristalizaron las revoluciones de independencia que pondrían fin a la estructura colonial de matriz hispana instalada en el continente desde hacía siglos.

La política de control objetivada y pragmatizada por la metrópoli motivó la acción de sujetos genuinos -criollos, mestizos, indios- en el marco de un choque de mentalidades que se evidenció en resistencias, rechazos y oposiciones claras a la implementación de diversas reformas ideadas en el Viejo Continente, por ejemplo, las reformas borbónicas ideadas con el objetivo de afrontar diversas problemáticas acaecidas en España, de manera muy sintética, la modernización de las estructuras existentes y la restauración del poder y prestigio de la Corona, a fin de orientarla hacia un renacer político, económico y cultural.

Puesto en práctica en el marco del despotismo ilustrado, durante el reinado de Carlos III, el reformismo contempló también los territorios de ultramar y, en el contexto de un proyecto centralista e integrador, se apuntó a una mayor concentración de poder monárquico, para lo cual resultó necesario eliminar los poderes locales y frenar las demandas de autonomía ejercidas por la naciente clase colonial.

Las reformas borbónicas abarcaron esferas como la económica, comercial, administrativa, religiosa y militar impactaron, por tanto, sobre el contexto americano y alteraron el equilibrio entre los diversos grupos de poder. Las medidas adoptadas se direccionaron hacia una mayor supervisión de la

38 “Tengo sobre mí los males de mi pueblo". Interpelación y advertencia desde el quehacer martiano Marina Verdini-Aguilar

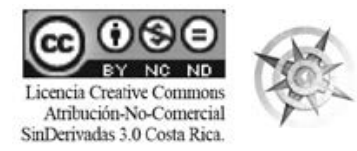


población americana que, como hemos señalado, no permaneció pasiva, sino que dio anuencia a un ciclo de conflictos frente al sometimiento peninsular. Al respecto, Fernando Mires sostiene que:

(...) cuando son implantadas reformas sobre estructuras sociales extremadamente rígidas tienden a producirse fisuras que son imposibles de cerrar (...) esta situación fue aprovechada bastante bien por algunos espíritus inquietos, pero sobre todo por algunos sectores sociales, para hacer sentir sus reivindicaciones. (1988, pp. 60, 62)

Así, las reacciones registradas desde el siglo XVI conformaron un registro de acumulación en el que se insertarán, en un tiempo distinto, las posteriores gestas independentistas.

Lo anteriormente señalado nos orienta a rescatar la revolucionaridad como cualidad que signa a nuestro continente y que emerge desde los primeros momentos en que se instala la dominación. Dicha cualidad nos invita entonces a pensar las luchas por las independencias en términos de procesos que esgrimen temporalidades amplias, excediendo el marco estricto de los primeros años del 1800. Este marco temporal extenso permite distinguir diversas fases, con caracteres propios, enhebradas en un mismo hilo conductor: la etapa "prerrevolucionaria" - de la segunda mitad del siglo XVIII a 1808-; la de "crisis y ruptura" -de 1808 a 1810 - y, por último, la etapa de "revoluciones de independencia" -1810-1825-.

En la etapa prerrevolucionaria distinguimos episodios caracterizados por la participación de los sectores subalternos, generalmente silenciados o negados por la historiografía liberal. A modo de ejemplos podemos mencionar dos, localizados en distintas partes de nuestro continente: para la Región Andina, el movimiento encabezado por José Gabriel Condorcarqui, conocido como Tupac Amaru, quién -según Fernando Mires- constituye el caudillo de la primera revolución social hispanoamericana; asimismo, en Venezuela encontramos la frustrada conspiración organizada por Manuel Gual y José María España. Llevado adelante en 1797, este episodio evidencia claramente la existencia de una conciencia del ser americano y la emergencia de un ideal libertario.

El período de crisis y ruptura se caracteriza por la inflexión que, a partir de 1808, marcan los acontecimientos acaecidos en Europa y, particularmente, en la Península Ibérica: la invasión de las tropas napoleónicas

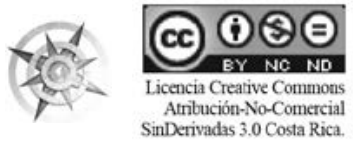

“Tengo sobre mí los males de mi pueblo". Interpelación y advertencia desde el quehacer martiano 
a España, el cautiverio de Fernando VII, la presencia de un monarca francés y la formación de juntas en resguardo de la soberanía del rey legítimo constituyen algunos nodos de un proceso que en nuestra América viraría desde la legitimación del monarca español y el interés por el autogobierno hacia la radicalización de la acción revolucionaria con propósitos rupturistas.

De esta manera, el ciclo independentista abierto en distintos frentes y la posterior construcción de los Estados Nacionales constituyen procesos que se distinguen por su complejidad y por las diversas aristas de análisis.

Remitirnos a tales cualidades de abordaje supone registrar los plurales contextos de desarrollo, los distintos marcos espacio-temporales y las características propias de las formas de organización de la reacción y resistencia. Si bien no es el objetivo de las presentes líneas problematizar la dinámica de dichos procesos, consideramos que debemos bosquejar algunos aspectos para poder abocarnos a la cuestión propia del artículo.

En este sentido, vale decir que junto con la crisis de la monarquía española a mediados 1808, en el Nuevo Continente, la lucha por el poder entre algunos sectores criollos y peninsulares comenzó a configurar el escenario marco de las futuras revoluciones que se desarrollaron paralelamente a partir de 1810 .

Dicho año se establece entonces como parteaguas que marca de manera neta el inicio de la etapa revolucionaria, mientras que el final del siglo XIX implicaría, para la América continental, la consolidación de las diversas naciones republicanas, construidas a lo largo de un itinerario que tampoco resultó sencillo ni homogéneo.

Refiriéndose a los intentos de organización estatal, Oszlak sostiene que estos “(...) no siempre fueron exitosos, y en muchos casos desembocaron en largos períodos de enfrentamientos regionales y lucha entre facciones políticas (...)" (1978, p. 27)

Parte de las complejidades mencionadas se relacionan con los diversos tiempos en los que se materializó la acción. Tomando de este modo el plural, consideramos que es posible identificar itinerarios que escapan del trayecto revolucionario trazado en el Continente. En este sentido el Caribe insular de matriz hispana constituye un ejemplo bifaz: por un lado ilustra el conservacionismo de la monarquía española -conservacionismo que perduró hasta finales

40 “Tengo sobre mí los males de mi pueblo". Interpelación y advertencia desde el quehacer martiano Marina Verdini-Aguilar

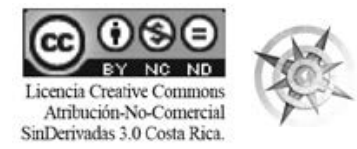


del siglo XIX-y, por otro, constituye una de las fugas que denotan que el dilema de la independencia (Guerra Vilaboy, 2007) no puede entenderse de manera rectilínea.

Es en el específico contexto caribeño en el cual se presenta la lucha independentista de la perla más grande de las Antillas, la isla de Cuba, y es en este proceso concreto en el que se despliega el accionar intelectual-político-revolucionario de José J. Martí.

Focalizar la mirada en el recorrido libertario isleño nos obliga a señalar que este abarca un extenso período en el que se destacan las denominadas "Guerra Grande", y "Guerra Chiquita" como intentos independentistas que no logran concretar su objetivo pero que sirven de antecedentes para el desarrollo del último conflicto armado situado en la Isla hacia fines del 1800: la "Guerra Necesaria"; esta planteó como objetivo norte la liberación nacional bajo la conducción del propio Martí y generales como Máximo Gómez, Antonio Maceo y Flor Crombet.

La Guerra Grande, conocida también como Guerra de los Diez Años, se libró entre 1868 y 1878 . Su iniciador fue el terrateniente, abogado y poeta Carlos Manuel de Céspedes y López del Castillo, dueño también del ingenio azucarero "La Demajagua" -ubicado en el Oriente de la Isla, a pocos kilómetros de Manzanillo-. Él dio el puntapié de la revolución el 10 de octubre de 1868 , al redactar un manifiesto en el que se exponían los principios del movimiento, el cual liberaba a los esclavos que trabajaban en sus plantaciones y libraba el primer combate en el poblado de Yara. En el conocido como "Grito de Yara" se unieron los terratenientes de la región, los esclavos, los pequeños agricultores y los medianos propietarios; a ellos se sumarían los levantamientos de Camagüey y Las Villas. No obstante, durante los diez años del combate, el movimiento no logró unificar la lucha ni construir las fuerzas necesarias para concretar el objetivo independentista. El "Pacto del Zanjón", firmado el 10 de febrero de 1878, puso fin a las hostilidades pero no al objetivo emancipatorio: desde el exterior y desde la propia Isla, miles de cubanos pretendían retomar la guerra.

La Guerra Chiquita inició el 24 de agosto de 1879 en Gibara y Holguín. El movimiento estuvo dirigido por el General Calixto García. A él se sumaron en su mayoría gente modesta, integrantes de la pequeña burguesía, negros, mulatos, profesionales liberales. José Maceo,

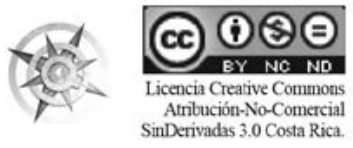

“Tengo sobre mí los males de mi pueblo”. Interpelación y advertencia desde el quehacer martiano 
Guillermo Moncada y Quintín Banderas direccionaron los lanzamientos en Santiago de Cuba, mientras que, en Matanzas y La Habana, los alzamientos fracasaron y le costaron la prisión a diversos combatientes, entre ellos José J. Martí. En poco tiempo, Maceo, Banderas y Moncada se rindieron ante los españoles, sy fueron enviados a diversos presidios en África; en septiembre de 1880 lo hizo el iniciador de la Guerra Chiquita, quien quince años después volvería al combate, al participar en la Guerra Necesaria.

La también denominada guerra Hispano-cubana con intervención norteamericana resultó entonces precedida por los mencionados ensayos y constituyó un conflicto de singular valor para la historia de la Isla, el Caribe y nuestra América toda. A la Guerra Hispano-Cubana, conflicto librado inicialmente entre Cuba y España, se sumaría, en febrero de 1898, Estados Unidos; la defensa de los intereses norteamericanos en la Isla tras la voladura del acorazado Maine, habilitó la participación del Gigante del Norte. Habiendo comenzado en 1895 , la guerra finalizó con el Tratado de París, firmado el 10 de diciembre de 1898. Se abrió así un nuevo período de hegemonía política y económica por parte de los Estados Unidos en el Caribe: Cuba pasó a ser protectorado de aquel país.

Por medio del senador O. Platt, el Secretario de Guerra E. Root propuso la limitación de la soberanía de la Isla, para salvaguardar los intereses de los Estados Unidos. Mediante la Enmienda Platt, se proponía el derecho de intervenir en los asuntos internos de la naciente república caribeña.

Asimismo, la decidida participación de Martí en el campo de batalla estuvo antecedida por una fase proselitista evidenciada en diversas piezas textuales. Como mencionamos, en esta oportunidad y a fin de realizar una lectura en clave histórica, seleccionamos una obra central de la producción martiana: el ensayo programático titulado Nuestra América².

El historiador cubano Pedro Pablo Rodríguez califica como programático en ensayo Nuestra América pues considera que es uno de los pocos casos en que se exponen no solo los objetivos del ideario martiano, sino también el conjunto de análisis que sustentaba sus conclusiones para hacer efectiva la acción política. Por ello, el texto puede ser asumido

2 En esta ocasión utilizaremos la publicación prologada por el ensayista cubano Cintio Vitier, editada en el 2006 por el Centro de Estudios Martianos.

\footnotetext{
42 “Tengo sobre mí los males de mi pueblo". Interpelación y advertencia desde el quehacer martiano Marina Verdini-Aguilar
}

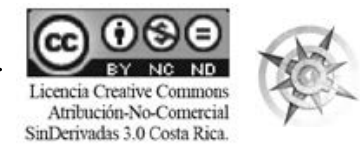


como un verdadero programa revolucionario para América Latina.

Un análisis desde dicha perspectiva requiere, en primera instancia, realizar una presentación de la fuente, la cual elegimos enlazar con diversos aspectos de la biografía del llamado Apóstol.

Concebido por diversos especialistas como uno de los textos fundamentales de la obra martiana, creemos que Nuestra América resulta una de las piezas claves para entender la praxis de nuestro autor, así como su análisis ontológico del continente, en el que se expresa ese deber ser del pensamiento martiano en tanto “(...) categoría propia y personal de entender el mundo que revela (...) su autoconciencia de americanidad" (Torre, 2007, p. 7).

El texto apareció, con diferencia de días, en dos publicaciones. Primeramente, en La Revista Ilustrada de Nueva York, a principios de enero de 1891, y hacia fines del mismo mes el ensayo era divulgado nuevamente en el periódico mexicano El Partido Liberal. ${ }^{3}$

3 Teniendo como público principal las familias que conformaban la basta comunidad de habla hispana residente en Nueva York y siendo propiedad de Elías de Losada, La Revista Ilustrada de Nueva York (1886-i1898?) se propuso como meta la difusión de la cultura y literatura hispanoamericana; para ello logró aglutinar a
En ese mismo año Martí se hallaba instalado en los Estados Unidos, puntualmente en la ciudad de Nueva York; allí había arribado en 1880 luego de una breve visita a Venezuela -en ese mismo año- y de recorrer, desde 1871, distintas regiones de la geografía latinoamericana y europea. En aquella ciudad norteamericana, con veintisiete años de edad, ocupó el cargo de vicepresidente del Comité Revolucionario Cubano, uno de los plurales espacios desde el que propugnó la necesidad de continuar con la gesta iniciada por Céspedes.

Su interés por el estudio de las diversas aristas de la sociedad lo llevó a inmiscuirse en la política, la economía así la cultura, como a analizarlos en distintos contextos espacio-temporales; indagó de tal modo en regiones lejanas tanto geográfica como temporalmente -el Antiguo Oriente y la Magna Grecia-, se aproximó a su siglo -ahondando tanto en la dinámica de los procesos independentistas como en la vida de sus líderes y actores colectivos- y estudió también

distintos escritores hispanoamericanos y de España, residentes en EE. UU.

En lo que respecta a El Partido Liberal, el periódico se publicó entre 1885 y 1896, subvencionado por el gobierno de Porfirio Díaz. Su suplemento, La Revista Azul, fundada el 6 de mayo de 1894 por Manuel Gutiérrez Nájera y Carlos Díaz Dufoo, es considerada la primera publicación periódica del modernismo en México.

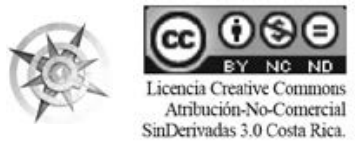

“Tengo sobre mí los males de mi pueblo”. Interpelación y advertencia desde el quehacer martiano Marina Verdini-Aguilar 
su propio presente. En este marco, la observación de la coyuntura estadounidense no fue la excepción.

Participó entonces de la Primera Conferencia Internacional Americana ${ }^{4}$ que, motivada principalmente por los intereses económicos norteamericanos, anticipaba una nueva forma de dominación. En este sentido, tanto el mencionado encuentro como la Conferencia Monetaria de las Repúblicas de América ${ }^{5}$ constituyen dos acontecimientos centrales que favorecieron el posicionamiento antiimperialista del cubano. Así, en el texto "La conferencia monetaria de las Repúblicas de América" advertía:

Lo real es lo que importa, no lo aparente. En la política, lo real es lo que no se ve (...) A todo convite entre pueblos hay que buscarles las razones ocultas. Ningún pueblo hace nada contra su interés; de lo que se deduce que lo que un

4 Realizada en Washington entre el 2 de octubre de 1889 y el 19 de abril de 1890 . Promovida por el Secretario de Estado norteamericano James Blaine, para encauzar el avance comercial y económico hacia el sur, cuestión que planteaba la posibilidad de anexionar nuevos territorios, entre ellos, Cuba. En este marco es pertinente recordar que desde 1823 otro Secretario de Estado -John Quincy Adamsseñaló que, por su ubicación geográfica, Cuba y Puerto Rico constituían «apéndices naturales» de Estados Unidos.

5 Realizada el 4 de febrero de 1891 en Washington. pueblo hace es lo que está en su interés. Si dos naciones no tienen intereses comunes, no pueden juntarse. Si se juntan, chocan. ${ }^{6}$ (Martí, 1992, p. 158)

De este modo, la segunda mitad del siglo XIX enmarca la redacción de nuestro documento. Una caracterización adecuada del período, que evite interpretaciones simplistas, excedería los límites de nuestro artículo; no obstante, nos arriesgaremos a realizar una síntesis.

En nuestra América, tales años se corresponden con la fase de elaboración del proyecto oligárquico ${ }^{7}$. Nos encontramos así con la fase inicial de la hegemonía oligárquica, es decir, "(...) de una clase cuyos orígenes son coloniales, que basa su poder en el control de los factores productivos y que utiliza directamente el poder político para aumentar su dominación sobre las restantes capas sociales." (Carmagnani, 1984, p.21)

Como parte constitutiva del proyecto encontramos la inserción de las economías latinoamericanas en la economía internacional, integración

$6 \quad$ El resaltado es nuestro.

7 Según el historiador M. Carmagnani, esta fase se inicia en 1850 y forma parte de un ciclo mucho más amplio que se extiende hasta 1930. En él encontramos, además, la etapa en que dicho proyecto se consolida $(1880-1914)$ y aquella en la que se desmorona (1914-1930).

44 “Tengo sobre mí los males de mi pueblo". Interpelación y advertencia desde el quehacer martiano Marina Verdini-Aguilar

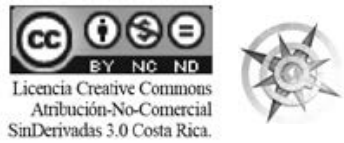


que también experimentó -tardíamente, a fines de siglo- la región central de nuestro continente.

Allí, el despliegue de las economías de enclave permitió la penetración, principalmente, del capital inglés y estadounidense, acompañado por el avasallamiento de la soberanía de los países centroamericanos; ello fue resultado del accionar de las compañías extranjeras y la presión e intervención ejercidas en las cuestiones nacionales. Un ejemplo claro lo constituyen las intervenciones militares de los Estados Unidos a favor de las empresas que lideraban el comercio de exportación. (Bethell, 1984)

Reduciendo la escala y enfocando nuestra mirada en la isla de Cuba, los años en cuestión se hallan signados por los tres episodios bélicos mencionados. Estos imprimieron en todas las esferas de la sociedad un clima de conflictividad; a ello se sumaron diversos factores que complejizaron el devenir isleño: las estrategias metropolitanas ${ }^{8}$ direccionadas a armonizar intereses

8 Nos referimos a una serie de medidas que reorganizaban municipal y provincialmente el territorio, poniendo en marcha un nuevo orden colonial. Como ejemplo podemos mencionar una legislación especial para Cuba -y Puerto Rico- representación parlamentaria, división de la Isla en seis provincias, mayores atribuciones para el Gobernador General, elecciones, entre otras. diversos; el surgimiento del sistema de partidos; la simultánea existencia de grupos conservadores -en sus distintas vertientes: reformismo, anexionismo, autonomismo- y de grupos que, principalmente desde el exilio, mantenían la actividad proindependentista, entre otros.

Es este el contexto de creación del ensayo; contexto que interpela al escritor y al resultado de su producción: un texto con un claro objetivo de concientización política.

Martí logró reconocer en su propio presente la convergencia de aspectos remanentes de la época colonial, junto con aquellos cambios resultantes de los procesos independentistas y de las medidas implementadas por los gobiernos latinoamericanos, encaminadas a consolidar el orden liberal capitalista. También identificó las incipientes manifestaciones hegemónicas de una nueva potencia neocolonial en emergencia: Estados Unidos.

El inicial interés estadounidense sobre nuestro continente cobraría un nuevo impulso con posterioridad a la Guerra de Secesión. Tal gravitación se halla legitimada por medio de una amplia tradición ideológica que encuentra su punto de partida en la bautizada por el periodista John L. O'Sullivan con el nombre

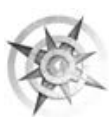


de Manifest Destiny (Destino Manifiesto): la colonización y la posesión del continente era el destino patente de los Estados Unidos. A partir de allí, se concretó la expansión y comenzó a demarcase un tiempo de yuxtaposición en la contracción colonialismo/imperialismo. Sin embargo, el despliegue de este último fenómeno sobre nuestra América se iniciará, coincidiendo con R. Fernández Retamar, a partir del $98 \mathrm{Cu}$ bano, episodio que daba anuencia a la presencia del imperialismo moderno, provisto de todas sus armas. (Retamar, 1998)

Queda entonces bosquejado este contexto pluricoyuntural en el que se desarrolló la praxis del cubano universal. La advertencia fue un aspecto nodal de su labor; por medio de la observación práctica, identificó múltiples cuestiones que se presentaban engarzadas a las tres instancias temporales: tuvo la capacidad para distinguir continuidades cuya génesis se encontraba en un pasado colonial compartido; pero también, desde el mismo Calibán", advirtió

9 Uno de los personajes de la obra La tempestad de W. Shakespeare. En la misma, Calibán es un salvaje primitivo, esclavizado por el protagonista, Próspero, y representa los aspectos más materiales e instintivos del ser humano. Esta figura es retomada por pensadores hispanoamericanos como José Enrique Rodó o Rubén Darío, quienes la igualan al materialismo de los EE. UU. Ver más en Pretti Javier, Gallegos, Claudio “Un problemáticas que se originaban en su propio presente y que a su vez se proyectarían sobre los comunes futuros de nuestro continente.

Sus creaciones literarias constituyeron una de las armas empuñadas para advertir e intervenir. Así, el itinerario experiencial de Martí y el contexto descripto se condensan en un ensayo que en clave histórica admite ser estudiado desde disímiles ejes: proceso/s, tiempo/s, espacio/s, actor/es. En esta oportunidad quisiéramos referirnos a la cuestión del tiempo en plural.

Reflexionar en torno a la problemática del/los tiempo/s histórico/s, en tanto una de las categorías nodales de nuestra labor disciplinar, resulta indispensable dado que el "(...) tiempo histórico o temporalidad constituye una herramienta necesaria para comprender la relación dialéctica entre el pasado, el presente y el futuro (...)" (Sauro, 2009, p. 119)

Este punto nos permite señalar que la concepción de un tiempo histórico único ha sido sometida a debate $y$, en la actualidad, es factible postular multiplicidades temporales, a fin de rescatar las distintas funcionalidades

otro Calibán: de los héroes nacionales al arquetipo del Tío Sam” en FEPAI, ISSN 0326-3339.

46 “Tengo sobre mí los males de mi pueblo". Interpelación y advertencia desde el quehacer martiano Marina Verdini-Aguilar

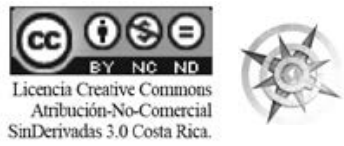


del tiempo a través de las cuales discurren los fenómenos históricos.

En este sentido, el pensamiento martiano se vincula dialécticamente con el análisis sistemático de su propio tiempo; a partir de ello fue capaz de dar forma a un proyecto para trastocar aquellas realidades que consideró injustas.

Es así que creemos que en sus escritos no hay palabras al azar, por el contrario, todo conlleva un propósito comunicativo, direccionándose hacia la búsqueda de un efecto, de una reacción y la fuente escogida no es la excepción. Reacción no como mero impulso desorganizado, sino como praxis que aúna el análisis teórico, la construcción de concepciones y categorías -que permiten la apropiación, el conocimiento de la realidad- junto con la intervención, con la acción política.

Encontramos entonces, en primer lugar, el tiempo que hace referencia al presente del autor, quien logra identificar el interés norteamericano por extender su influencia económica y política sobre distintas zonas del continente. El Gigante del Norte podía poner sus botas sobre las nacientes repúblicas americanas, por ello Martí sentenció:
Estos tiempos no son para acostarse con el pañuelo a la cabeza, sino con las armas de almohada (...) las armas del juicio, que vencen a las otras. ${ }^{10}$ (Martí, 2006, p. 35)

"Estos" -aquellos- tiempos demandan el autoconocimiento de los pueblos nuestroamericanos, emprendiendo así una labor fundamental en el ideario de nuestro pensador: reconocerse a sí mismos y conocerse entre sí.

Esta propuesta martiana es parte de su accionar libertario y creador, dado que conocernos implica des-cubrir lo ocultado a través de la negación, de la adjetivación peyorativa, de la dicotomía civilización-barbarie implementadas tras siglos de dominio colonial; frente a ese existir inauténtico ${ }^{11}$, la valoración y connotación positiva.

Este paso era esencial para dejar de ser individuos de "siete meses", esos "(...) insectos dañinos que le roen el hueso a la patria que los nutre [esos] nacidos en América, que se avergüenzan, porque llevan delantal indio (...)" (Martí, 2006, p. 37)

Se alternaban y conjugaban el tiempo del conocimiento y los tiempos

10 El resaltado es nuestro.

11 Categoría del filósofo Augusto Salazar Bondy. Este concepto alude a la ocultación, consciente o inconsciente, de nuestro verdadero ser, pretendiendo ser lo que no somos. 
de la construcción-creación de caminos propios para sortear las encrucijadas que se le presentaban a Cuba y al Continente:

La incapacidad no está en el país naciente, que pide formas que se le acomoden y grandeza útil, sino en los que quieren regir pueblos originales $(\ldots)$ con leyes heredadas de cuatro siglos de práctica libre en los Estados Unidos, de diecinueve siglos de monarquía en Francia. (Martí, 2006, p. 38)

Paralelamente, Martí señaló que se aceleraban los tiempos de preparación para la acción libertaria; la labor proselitista precedía la fase organizacional de la futura revolución necesaria y en tal sentido convocó a la unidad frente a los regionalismos:

Los pueblos (...) que se enseñan los puños (...) han de encajar, de modo que sean una, las manos (...) Es la hora del recuento y de la marcha unida y hemos de andar en cuadro apretado, como la plata en las raíces de los Andes (Martí, 2006, pp. 35, 36)

Así, el ensayo presenta un claro devenir en el pensamiento y en los planes del isleño, estableciendo y aunando escalas que van desde lo local hacia lo continental. Cuba quedaba enmarcada nítidamente en un cuadro mayor, en un itinerario más amplio, el latinoamericano. De esta manera, se torna evidente el tiempo de la síntesis, de la conjunción de procesos: el ciclo de las independencias de matriz hispana -abierto en 1810 - se engarza con la temporalidad propia que signa al trayecto de resistencia de la Isla, resistencia que se trasmuta en lucha independentista.

Los tiempos de la organización y del necesario triunfo de la independencia cubana se articulan con los tiempos de concreción de un nuevo tipo de dominación: el imperialismo yanqui que, como mencionamos anteriormente, se manifestó con contundencia en 1898. Una vez más, se conjugan tiempos: el momento de concretar la guerra de independencia contra España coincide con el de llevar adelante la primera batalla antiimperialista en América:

Pero otro peligro corre, acaso, nuestra América (...) El desdén del vecino formidable que no la conoce es el peligro mayor de nuestra América; y urge, porque el día de la visita está próximo, que el vecino la conozca (...) para que no la desdeñe (...) en el amasijo de pueblos se condensan (...) las ideas y los hábitos de ensanche y adquisición, de vanidad y avaricia que (...) pudieran, en un período de desorden interno

48 “Tengo sobre mí los males de mi pueblo". Interpelación y advertencia desde el quehacer martiano Marina Verdini-Aguilar

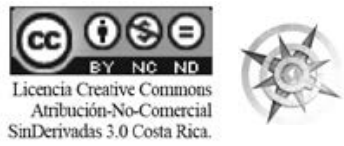


o de precipitación del carácter acumulado de un país, trocarse en amenaza grave para las tierras (...) que el país fuerte declara perecederas e inferiores. (Martí, 2006, pp. 49,50)

Observa Martí que las bases del desdén de los EE. UU. se encuentran en su desenfreno, ambición y una tradición de conquista que pervivía en aquellos tiempos en los que América ya había obtenido sus independencias para encarar la construcción y consolidación de los Estados Nacionales.

Finalmente, este último aspecto merece ser resaltado. En 1891, el autor logró inferir y advertir las intenciones, objetivos y estrategias imperialistas a través de un estudio histórico-social. Martí desafió así las concepciones positivistas que demandan un alejamiento, un distanciamiento temporal como condición indispensable de la objetividad que debe regir toda investigación y dedicó su vida a analizar profundamente su propio presente para poder trastocarlo positivamente.

\section{Conclusiones}

Como hemos mencionado, apelar a la categoría tiempo resulta inevitable para quienes ejercemos la disciplina histórica. Indagar respecto a dicha categoría -y a todas aquellas que conforman nuestro andamiaje teórico-metodológico- es investigar, en parte, en torno a nuestra profesión, a las epistemologías que la sustentan, se complementan o pugnan entre sí.

En este marco, y coincidiendo con el intelectual portugués B. de Sousa Santos, la epistemología occidental dominante

(...) fue construida a partir de las necesidades de dominación capitalista y colonial y se asienta en lo que designo pensamiento abismal. Este pensamiento opera por la definición unilateral de líneas radicales que dividen las experiencias, los actores y los saberes entre los que son visibles, inteligibles o útiles. Así, la realidad social es dividida en dos universos (...) La división es tal que "el otro lado de la línea" desaparece como realidad, se convierte en no existente, y de hecho, es producido como no existente. ${ }^{12}$ (De Sousa Santos, 2010, p. 8)

Esta epistemología de herencia occidental y moderna no puede desvincularse de un fenómeno complejo que exhibe múltiples aristas: la colonialidad. Como bien lo explican E. Restrepo y A. Rojas,

12 El resaltado es nuestro.

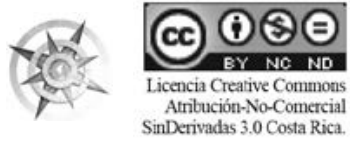

“Tengo sobre mí los males de mi pueblo”. Interpelación y advertencia desde el quehacer martiano Marina Verdini-Aguilar 
La colonialidad es un fenómeno histórico (...) que se extiende hasta nuestro presente y se refiere a un patrón de poder que opera a través de la naturalización de jerarquías territoriales, raciales, culturales y epistémicas, posibilitando la re-producción de relaciones de dominación ${ }^{13}$ (2010, p. 15)

Es posible distinguir, entonces, una colonialidad del enunciar, del ser, del poder y del saber, en tanto manifestaciones de este “(...) esquema de pensamiento y marco de acción que legitima las diferencias entre sociedades, sujetos y conocimientos (...)" (Restrepo y Rojas, 2010, p. 16)

Por lo tanto, la colonialidad resulta una cuestión que se diferencia del colonialismo y no se agota en este, incluyendo así experiencias y articulaciones que operan en nuestro presente.

Es por ello que desde diversas disciplinas se han presentado voces que enuncian "paradigmas otros" (Mignolo, 2003, p. 20) y apuestan a un necesario "ir más allá" de las categorías de análisis y de las disciplinas modernas.

De esta manera, abrirnos hacia otras formas de concebir el tiempo de/en los procesos históricos

13 El resaltado es nuestro. -saliéndonos del paradigma positivista $^{14}$ - resulta una invitación para retomarlo desde nuestra experiencia político-continental

(...) Esto implica no el desconocimiento de la construcción y despliegue de la modernidad, sino superar una actitud pasiva y resignada o lo que es peor imitativa esperando resultados de aplicación homogéneos; (Rodríguez, Rodríguez Fernández y Verdini, 2011, p. 388)

Creemos que resulta enriquecedor reconocer la heterogeneidad de los tiempos y espacios; historizar el tiempo, poniendo en cuestión el singular establecido desde la perspectiva eurocéntrica; rescatar así contenidos auténticos, genuinos -comúnmente desalojados por el pensamiento hegemónico-, elaborando una temporalidad propia que no invisibilice otras temporalidades.

Desde este posicionamiento y con estos intereses nos hemos acercado a la praxis martiana. La vastedad de su vida y obra son permeables a ser analizadas desde enfoques múltiples que, en tanto se complementan, nos

14 En este marco el tiempo es entendido en línea recta, en un sentido único; se prioriza la selección de hechos políticos, militares o económicos de relevancia; hitos que atraviesan de manera total y universal las sociedades, desde un punto de vista eurocéntrico.
50 “Tengo sobre mí los males de mi pueblo". Interpelación y advertencia desde el quehacer martiano Marina Verdini-Aguilar
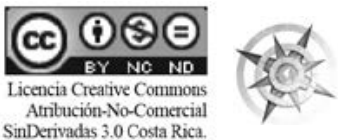
permiten obtener una visión cada vez más integral e interesante.

Situado en un "(...) torbellino de corrientes (...)" (Domínguez Hernández, 1989, p. 127), a caballo entre dos siglos, consideramos que si bien tuvo conocimiento de diversas escuelas de pensamiento -como el positivismo y el krausismo- su figura no resiste encasillamiento o clasificación alguna. Su trayectoria se encuentra nutrida por y distanciada de las principales corrientes del momento así como condensa un giro en el pensamiento histórico, filosófico y político-social de la época.

No es posible entender a Martí si se aleja de los objetivos faro que guiaron su praxis; si no se estudia a la luz de su innegable carácter revolucionario y su labor independentista y antiimperialista.

En palabras de C. Beorlegui:

Martí fue un pensador peculiar, no un «pensador de lámpara», como él decía, sino un pensador veerdor, analista, fundador y transformador de realidades (...) atravesado por dos creencias fundamentales: «la creencia rectora de que el hombre que se quiere humano, tiene que echar su suerte con los pobres, o hacer causa común con los oprimidos»; y «la no menos fuerte creencia de que sin el desarrollo pleno y libre de lo particular-diverso no se podrá alcanzar jamás una universalidad digna de este nombre» (2004, p. 334)

\section{Referencias bibliográficas}

Beorlegui, C. (2004). Historia del pensamiento filosófico latinoamericano. Una búsqueda incesante de la identidad. Bilbao: Deusto.

Carmagnani, M. (1984). Estado y sociedad en America Latina. 1850.1930. Barcelona: Crítica.

Cerutti-Guldberg, H. (2011). Pensando después de 200 años. México: Colección Altos Estudios.

Domínguez-Hernández, M. (1989). Lengua y crítica en José Martí. La Habana: Pablo de la Torriente.

Fabelo Corzo, J. La obra de José Martí: fusión de poesía y filosofía. Estudio. Poética y poesía. Revista de la Facultad de Filosofía y Letras. Recuperado de http://www.filosofia.buap.mx/Graffylia/3/104.pdf N. ${ }^{\circ}$, pag. 104-110.

Fernández Retamar, R. (2009). Anuario del Centro de Estudios Martianos. La Habana: CEM.

Martí José, (1993). José Martí. Epistolario. Tomo I. 1862-1887. La Habana: Ciencias Sociales.

La conferencia monetaria de las Repúblicas de América. En Biblioteca Virtual Universal. Recuperado de http://www. biblioteca.org.ar/libros/155149.pdf

Obras completas VI. La Habana: Ciencias Sociales. 
Miranda, J. (Pról.). (2003). Escenas norteamericanas. Caracas: Arte.

Rivas Toll, E. (2008). Reflexiones en torno a la filosofía de José Martí en el contexto de la filosofía latinoamericana A parte rei. Revista de Filosofía, (49). Recuperado de http://serbal.pntic. mec.es/ cmunoz11/rivas49.pdf

Rodríguez, A., Fernández, A. y Verdini Aguilar, M. (2011, agosto 29, $30 \mathrm{y}$ 31) El 98 cubano entre dos fuegos colonialismo e imperialismo en la base de un abordaje teórico. Ponencia presentada en las IV Jornadas de Investigación en Humanidades. Homenaje a Laura Laiseca, Bahía Blanca. Recuperado de http://www.jornadasinvhum.uns. edu.ar/pdf/ACTAS\%20IV\%20JORNADAS\%20-\%20Completas.pdf

Vitier, C. (2006). Nuestra América. José Martí. La Habana: CEM. 